\title{
Optimisation of electrophoretic deposition parameters for gas diffusion electrodes in high temperature polymer electrolyte membrane fuel cells
}

\author{
Cecil Felix, Ting-Chu Jao, Sivakumar Pasupathi and Bruno G. Pollet
}

\begin{abstract}
Electrophoretic deposition (EPD) method was used to fabricate gas diffusion electrodes (GDEs) for high temperature polymer electrolyte membrane fuel cells (HT PEMFC). Parameters related to the catalyst suspension and the EPD process were studied. Optimum suspension conditions are obtained when the catalyst particles are coated with Nafion ${ }^{\circledR}$ ionomer and the $\mathrm{pH}$ is adjusted to an alkaline range of about 8 e10. These suspensions yield good stability with sufficient conductivity to form highly porous catalyst layers on top of the gas diffusion layers (GDLs). GDEs were fabricated by applying various electric field strengths of which $100 \mathrm{~V} \mathrm{~cm}^{-1}$ yields the best membrane electrode assembly (MEA) performance. Compared to an MEA fabricated by the traditional hand sprayed (HS) method, the EPD MEA shows superior performance with a peak power increase of about $73 \%$ at similar platinum (Pt) loadings. Electrochemical Impedance Spectroscopy (EIS) analysis shows lower charge transfer resistance for the MEA fabricated via the EPD method compared to the HS MEA. The EPD GDE exhibits a greater total pore area $\left(22.46 \mathrm{~m}^{2} \mathrm{~g}^{-1}\right)$ compared to the HS GDE $\left(13.43 \mathrm{~m}^{2} \mathrm{~g}^{-1}\right)$ as well as better dispersion of the Pt particles within the catalyst layer (CL).
\end{abstract}

\section{Introduction}

Fuels cells are considered the most technically viable solution for a clean and sustainable future energy scenario. Fuel cells are similar to batteries i.e. they are both galvanic cells with the exception that the reactants are not permanently contained in the electrochemical cell but are fed from an external source when power is needed [1]. As long as the fuel (hydrogen or hydrogen rich media) and oxidant (oxygen or air) are supplied, the fuel cell will generate electrical energy, heat and water, eliminating the need for a long recharging process. Polymer Electrolyte Membrane Fuel Cells (PEMFC) are especially interesting due to their inherent advantages such as high power density, reduced system weight, simplified construction, rapid startup and low or no emissions. PEMFCs are suitable for portable, transport and stationary applications $[2,3]$. The main component of the PEMFC is the MEA which consists of a proton conducting membrane located between two porous, electrically conductive 
electrodes (anode and cathode) [4]. Electrochemical reactions, both anodic and cathodic, take place at the electrodes and are promoted by the use of a catalyst. Pure Pt or Pt in combination with other Platinum Group Metals (PGM), either supported or unsupported, is the most suitable for electrochemical reactions in PEMFC. Because of the use of Pt and PGM, the MEA represents the most expensive component of the PEMFC, therefore active research is carried out for improving catalyst utilisation. There are several MEA fabrication methods which alter the way the CL is formed. Each method is aimed at improving MEA performance and reducing the catalyst loading and thereby the overall cost. The CL can be deposited either onto the GDL known as Catalyst Coated Substrate (CCS) or directly onto the membrane known as Catalyst Coated Membrane (CCM) [5]. Catalyst deposition methods include spraying, hand brushing, direct printing, screen printing, decal transfer, electrodeposition, DC magnetic sputtering, EPD and even combinations of these methods [6]. An ideal MEA fabrication method should be reproducible, fast and up scaling should be possible [7]. EPD is a highly efficient process for the production of films and coatings; it is easy to implement, low cost, fast and applicable to a wide variety of materials [8]. EPD is achieved via the motion of charged particles, suspended in a liquid, towards an electrode under the influence of an applied electric field (electrophoresis). Deposition occurs when the particles collect via coagulation at the electrode surface and form a relatively compact and homogeneous film $[9,10]$. EPD has already been successfully demonstrated for the deposition of CLs in MEAs where deposition was achieved both on electron-conducting substrates (like GDLs), which simultaneously served as one of the electrodes as well ionconducting substrates (like proton conducting membranes) where the membrane was placed between two external electrodes [11e15]. Louh et al. [13] used EPD to deposit microporous layers (MPL) onto the carbon textile to form GDLs, followed by the deposition of the catalyst material to form GDEs. The deposited MPL and CL formed a continuous porous structure with the carbon textile, which reduced the impedance between the electrodes in the fuel cell and resulted in improved electrical conductivity of the MEA. Morikawa et al. [15] showed that the EPD process has selectivity for particle size since they only observed fine carbon particles in the deposited layer. Such selectivity for particle size should produce deposits of high uniformity and thereby increase Pt utilisation. From cyclic voltammetry (CV) and carbon monoxide (CO) adsorption experiments they calculated Pt utilisation of $56 \%$.

Munakata et al. [11] used the EPD method to deposit the catalyst particles directly onto a Nafion ${ }^{\circledR}$ membrane to form the MEA. They observed CLs that were well attached to the membrane and also the EPD process was selective towards particle size. Their EPD MEAs showed better performance than the hot press MEA with a maximum of $76 \% \mathrm{Pt}$ utilisation, compared to $28 \%$ Pt utilisation obtained by the hot pressing method. In their findings, these researchers applied the EPD process for fabrication of MEAs for low temperature polymer electrolyte membrane fuel cells (LT PEMFC) where the perfluorosulphonic acid (Nafion ${ }^{\circledR}$ ) membrane was used [16]. However Nafion ${ }^{\circledR}$ membranes are limited to operation temperatures of $80^{\circ} \mathrm{C}$, due to dehydration and loss 
of conductivity of the membrane. An operating temperature limited to $80{ }^{\circ} \mathrm{C}$ poses a serious impediment for the commercialisation of PEMFCs; heat rejection for automobile applications are difficult and $\mathrm{CO}$ which is present in the hydrogen fuels at concentration levels $>10 \mathrm{ppm}$, easily poisons the Pt active sites $[17,18]$. Thus there is a requirement for pure hydrogen which adds additional purification steps which in turn add to the production cost of PEMFCs. However, these limitations can be overcome by operating the fuel cell at temperatures above $80{ }^{\circ} \mathrm{C}$. For example, at higher temperatures faster reaction rates are achieved, generated water is easily removed because it is in the vapour phase and the Pt catalyst become more tolerant to CO poisoning [19]. Other advantages are reduced system weight, volume and complexity which results in increased power density, specific power and functionality through system and component simplification [20]. HT PEMFCs usually operate above $120{ }^{\circ} \mathrm{C}$ and commonly use phosphoric acid doped PBI membranes. However, the main drawback of HT PEMFCs is they require significantly higher Pt loadings (0.6e1.2 $\mathrm{mg} \mathrm{cm}^{-2} \mathrm{Pt}$ on each side) than LT PEMFCs $[21,22]$. Therefore, it is necessary to identify alternative MEA fabrication methods in order to improve the efficiency and reduce the Pt loading. In this study we applied the EPD process to fabricate GDEs to form MEAs for HT PEMFCs.

\section{Material and methods}

\subsection{Materials}

HiSpec 4000, 40 wt\% Pt/C (Alfa Aesar, Johnson Matthey, United Kingdom) was used as received, as catalyst material for all experiments. Nafion ${ }^{\circledR}$ solution, 5 wt\% (Johnson Matthey, United Kingdom) was selected as binder and ionomer to improve formation of the Triple Phase Boundary (TPB). Isopropanol (Kimix, South Africa) was used as suspension medium. $\mathrm{HClO}_{2}$ (Kimix, South Africa) and $\mathrm{NaOH}$ (Kimix, South Africa) was used to adjust the $\mathrm{pH}$ of the catalyst suspensions. A commercially available GDL, H2315 CX196 (Freudenberg, Germany) was used as received. A commercially available poly-(2,5benzimidazole), also known as the ABPBI membrane, Fumapem ${ }^{\circledR}$ AM (Fumatech, Germany) was doped in $\mathrm{H}_{3} \mathrm{PO}_{4}$ (Kimix, South Africa) for $24 \mathrm{~h}$ at $85^{\circ} \mathrm{C}$ prior to use.

\subsection{Zeta potential and particle size}

Measurement of electrophoretic mobility and particle size of $\mathrm{Pt} / \mathrm{C}$ particles in isopropanol were obtained using the Zetasizer Nano ZS (Malvern Instrument Ltd., United Kingdom). The instrument is fitted with a production standard $532 \mathrm{~nm}, 50 \mathrm{~mW}$ diode laser source. The zetasizer instrument measures electrophoretic mobility via a 3M-PALS method which is a combination of Laser Doppler Velocimetry (LDV) and Phase Analysis Light Scattering (PALS). Particle size was obtained via Dynamic Light Scattering (DLS) performed in a back scattering mode. Homogeneous catalyst inks were obtained by ultrasonically (20 $\mathrm{kHz}$ ) mixing the $\mathrm{Pt} / \mathrm{C}$, Nafion ${ }^{\circledR}$ ionomer and isopropanol for 5 min via the Biologics 3000 ultrasonic homogenizer (Biologics, Inc., USA) fitted with micro tip ultrasonic finger. The power of the homogenizer was set at 40\% with pulser set to the off position (o\%). The $\mathrm{pH}$ of the suspensions was monitored using the Metrohm $827 \mathrm{pH}$ lab (Metrohm, 
Switzerland) equipped with a Primatrode $\mathrm{pH}$ electrode. A syringe was used to fill a semidisposable capillary cell with the sample which was then immersed into a temperature controlled block holder to avoid thermal gradients in the absence of the applied electric field [23]. Electrophoretic mobility of particles was measured by applying a fixed voltage of $100 \mathrm{~V} \mathrm{~cm}^{-1}$. Electrophoretic mobility data was used to calculate zeta potentials using the Smoluchowski equation (Eq. 1).

$$
u=\varepsilon \varepsilon_{0} \zeta E / \eta
$$

where $\xi$ is the zeta potential, $E$ is the electric field strength and 330 and $\mathrm{h}$ are the dielectric constant and the viscosity of dispersion medium respectively. All measurements were performed at $25^{\circ} \mathrm{C}$.

\subsection{Fabrication of MEAs by EPD}

Catalyst inks were obtained by mixing Pt/C, Nafion ${ }^{\circledR}$ ionomer and isopropanol. The $\mathrm{Pt} / \mathrm{C}$ composition was $0.5 \mathrm{mg} \mathrm{ml}^{-1}$ of isopropanol and the Nafion ${ }^{\circledR}$ ionomer content was varied from 10 to $30 \mathrm{wt} \%$ with respect to the $\mathrm{Pt} / \mathrm{C}$ particle content. The $\mathrm{pH}$ of the suspensions was also adjusted to improve suspension conductivity. Ultrasonic agitation for 15 min ensured well dispersed catalyst inks. A microelectrophoresis power supply (Consort, Belgium) was used to deposit the catalyst particles onto the GDLs by varying the applied electric field strength and EPD duration. The obtained GDEs were placed in a vacuum oven (Binder GmbH, Germany) at room temperature and heated to $50{ }^{\circ} \mathrm{C}\left(w 1.5^{\circ} \mathrm{C} \mathrm{min}^{-1}\right.$ ) to dry the catalyst layer. The MEA was obtained by sandwiching the anode and cathode GDEs and the acid doped membrane together inside a single cell fixture. GDEs fabricated by the HS method were assembled in a similar way and evaluated for comparison. No prior hot pressing step was performed on the as-prepared MEAs. The EPD GDE based MEAs are termed EPD MEAs and the HS GDE based MEAs are termed HS MEAs.

\subsection{Electrochemical characterisation of MEAs}

An in-house HT PEMFC setup was used to study the electrochemical properties of the MEAs. The in-house HT PEMFC setup consisted of a PC loaded with Labview software to control the electronic load (Höcherl\&Hackl GmbH, Germany) and mass flow controllers (Bronkhorst, Netherlands). A cell compression unit (Pragma Industries, France) controlled the cell pressure and temperature. All measurements were carried out at $160{ }^{\circ} \mathrm{C}$ and a cell compression pressure of 20 bar with dry air and hydrogen. MEAs were activated for $3 \mathrm{~h}$ at $0.55 \mathrm{~V}$ followed by measuring the polarisation curve between open circuit voltage (OCV) and $0.3 \mathrm{~V}$. An impedance analyser (FuelCon, Germany) was used for EIS analysis in a frequency range of $0.1 \mathrm{e} 5 \mathrm{O}, 00 \mathrm{OHz}$.

\subsection{Physical characterisation of GDEs}


Morphology of the GDEs was characterised by Scanning Electron Microscopy (SEM) using the Carl Zeiss Auriga HRFEGSEM working at $20 \mathrm{kV}$. Porosity of GDEs was characterised by mercury intrusion porosimetry using the Autopore IV 9510 (Micromeritics, USA) mercury porosimeter applying pressures between 0.0145 and 4136.85 bar.

\section{Results and discussions}

\subsection{Catalyst ink characterisation}

Stable catalyst suspensions are important for the formation of homogeneous catalyst deposits. Particles in a solution become surrounded by ions of opposite charge in a higher concentration than the bulk concentration of these ions, to form the "so-called" doublelayer. Under the influence of an electric field the particle and ions should move in opposite directions, however because the ions are also attracted by the particle, some of the ions will move along with the particle. Particle mobility is thus not determined by the surface charge but by the net charge enclosed in the liquid sphere which moves along with the particle. The potential at the surface of shear is known as the zeta potential (z) [24]. Zeta potential plays an important role in stabilising the suspension and determining the direction and migration velocity of the particles. The overall stability of the suspension depends on the interaction between individual particles. Interaction between particles is affected by two mechanisms, namely the electrostatic and Van Der Waals forces. A high electrostatic repulsion due to a high particle charge is required to avoid particle agglomeration [25]. Thus stable suspensions suitable for successful EPD are those that contain particles that have a high zeta potential while maintaining a low ionic conductivity. Controlling particle size is also important as larger particles tend to sediment due to gravity. Particles that are undergoing sedimentation during EPD tend to give a gradient in deposition. This means that a substrate positioned vertically will have a thinner deposit above and a thicker deposit below. Fig. 1 shows the zeta potential of $\mathrm{Pt} / \mathrm{C}$ particles and Pt/C particles coated with Nafion ${ }^{\circledR}$ ionomer between $\mathrm{pH} 2$ and 12. For stable suspensions, zeta potential values ;:: $30 \mathrm{mV}$ or $-30 \mathrm{mV}$ depending on the particle charge is recommended. The isoelectric point occurs when the particles have a zeta potential value of $\mathrm{o} \mathrm{mV}$, however, no isoelectric point is observed over the whole $\mathrm{pH}$ range studied. At zeta potential values of $\mathrm{o} \mathrm{mV}$ to $\pm 10 \mathrm{mV}$, particle coagulation or flocculation occurs rapidly and particles would either sediment to the bottom or float on top of the solution. The zeta potential from $\pm 10 \mathrm{mV}$ to $\pm 30 \mathrm{mV}$ means incipient instability. For the uncoated $\mathrm{Pt} / \mathrm{C}$ particles in isopropanol, low values of zeta potential is observed at $\mathrm{pH} 2$ and 3 thus unstable suspension behaviour is expected. Highest zeta potential values are observed between pH 5 and 7 followed by decreasing zeta potential values as $\mathrm{pH}$ is increased to higher alkaline $\mathrm{pH}$ values. Suspensions containing Pt/C particles coated with Nafion ${ }^{\circledR}$ ionomer have higher zeta potential values than the uncoated $\mathrm{Pt} / \mathrm{C}$ particles in the acidic range whereas these particles possess lower zeta potential values as the suspension becomes more alkaline. Fig. 1 also shows that as the Nafion ${ }^{\circledR}$ ionomer content increases, the particles obtain a higher zeta potential value. Comparing the data in Fig. 1 with those in the work carried out by Louh et al. [12], a similar trend for the Nafion ${ }^{\circledR}$ coated Pt/C particles is observed, however, for the uncoated $\mathrm{Pt} / \mathrm{C}$ particles, they observed a continual increase of the zeta potential value as the $\mathrm{pH}$ increased to $\mathrm{pH}$ 12. By examining the particle size results as shown in Fig. 2, a clear relation can be made 
between the zeta potential and particle size for the uncoated $\mathrm{Pt} / \mathrm{C}$ particles in isopropanol, i.e. at acidic $\mathrm{pH}$ (2e4) and alkaline $\mathrm{pH}$ (11e12) where zeta potential values are lowest, particle size shows significant increase due to particle coagulation.

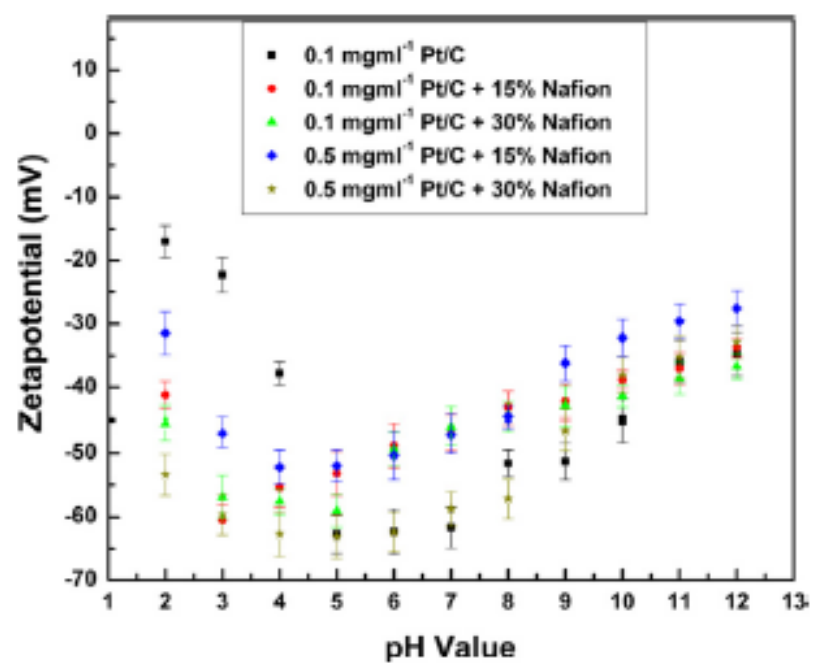

Fig 1. Zeta potential vs $\mathrm{pH}$.

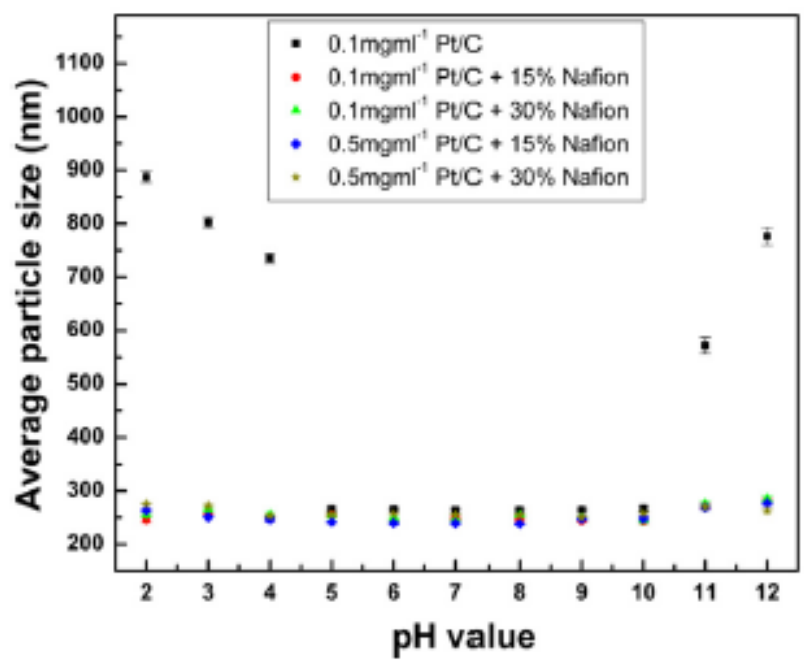

Fig 2. Average particle size vs $\mathrm{pH}$. 


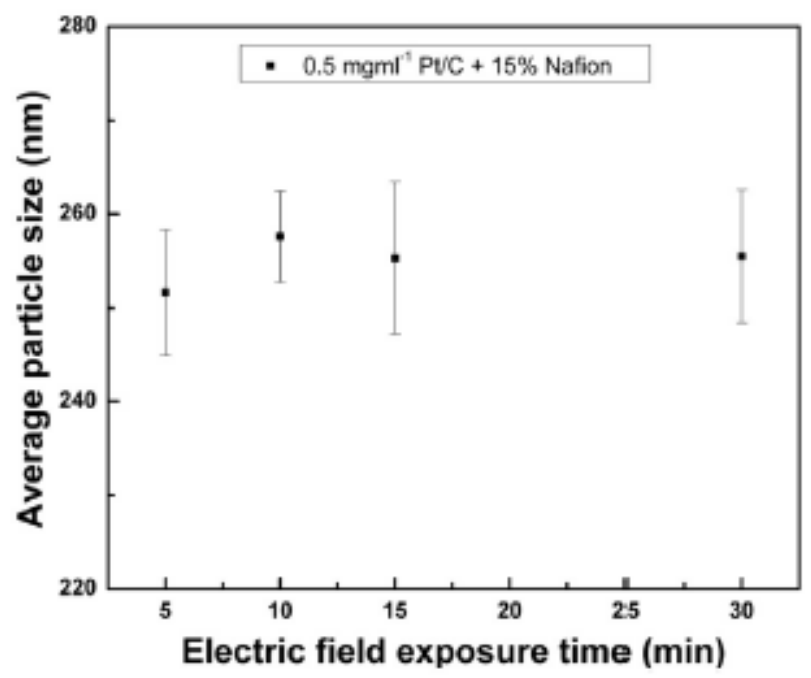

Fig. 3. Average partide size vs electric field exposure time.

The particle size for Pt/C particles coated with Nafion ${ }^{\circledR}$ ionomer is stable over the whole $\mathrm{pH}$ range studied clearly demonstrating the steric stabilisation effect of the Nafion ${ }^{\circledR}$ ionomer. Even at higher $\mathrm{Pt} / \mathrm{C}$ particle concentration no significant changes in particle size are observed. Nafion ${ }^{\circledR}$ acts as a surfactant as well as an active component of the catalyst layer structure. Nafion ${ }^{\circledR}$ is an amphiphilic polymer, consisting of a hydrophobic fluoro-backbone and a hydrophilic sulphonic acid group which is readily ionised and negatively charged to impart an electrostatic force on the $\mathrm{Pt} / \mathrm{C}$ particles [26]. As the Pt/C particles approach each other, the sulphonic acid side chain apposes attraction causing steric repulsion due to the unfavourable decrease in conformational entropy. Colloidal surfaces are thus maintained at distances large enough to damp any attractions due to the depletion effect or London-van der Waals forces and the colloidal suspension is stabilised [27]. Sterically stabilised systems tend to remain stable even at high salt concentrations [28] and conditions were the zeta potentials of the surfaces are reduced to near zero. However, besides high values of particle zeta potential, sufficient suspension conductivity is also crucial for the EPD process. When suspension conductivity is too high the particle motion is very low and when the conductivity is too low the suspension becomes too resistive and the particles become electronically charged and stability is lost [25]. A suspension $\mathrm{pH}$ of 9 was selected to fabricate the GDEs as this provided sufficient ionic conductivity for EPD.

Fig. 3 shows the average particle size obtained after subjecting the particles to an applied electric field of $100 \mathrm{~V} \mathrm{~cm}^{-1}$ for various time intervals between 5 and $30 \mathrm{~min}$. The average particle size is between 245 and $263 \mathrm{~nm}$ for the time intervals studied; the small increase in average particle size should not present a significant problem for the EPD process. This result implies that particle coagulation is slow even when an electric field is applied over a period of $30 \mathrm{~min}$ and that the particle size will not be significantly affected from the beginning to the end of EPD. 


\subsection{GDE fabrication and physical characterisation}

The driving force for the catalyst particles movement is the magnitude of the applied electric field; the higher the applied electric field strength the faster the particles will move towards the target. The applied electric field should also be sufficiently high to overcome the viscous drag and other forces exerted by the counter ions surrounding the particles. For fluid flow, the driving force and distance affects the flow field. In this study, an in-house EPD cell was constructed and used. Fig. 4 shows a schematic diagram of the in-house EPD cell. This cell construction allows fixing the distance between working and counter electrode to $1.8 \mathrm{~cm}$. It is important to reduce the distance between the working and counter electrode as greater distances requires stronger electric fields, which lead to a more energy intensive process and higher process costs. Fig. 1 shows that over the whole $\mathrm{pH}$ range studied, the particles are negatively charged and would therefore deposit onto the positively charged electrode. In order to obtain the desired Pt loadings, a calibration curve for the Pt loading with the applied electric field strength and deposition time was constructed. The calibration curve for $\mathrm{Pt}$ loading obtained at various applied electric field strengths and deposition time is shown in Fig. 5. It is clear from the calibration curve that the catalyst particles are deposited more rapidly as the applied electric field strength increases. The increase of the Pt loading is not linear which can be explained by the increased resistance as the catalyst layer thickens [15,25].

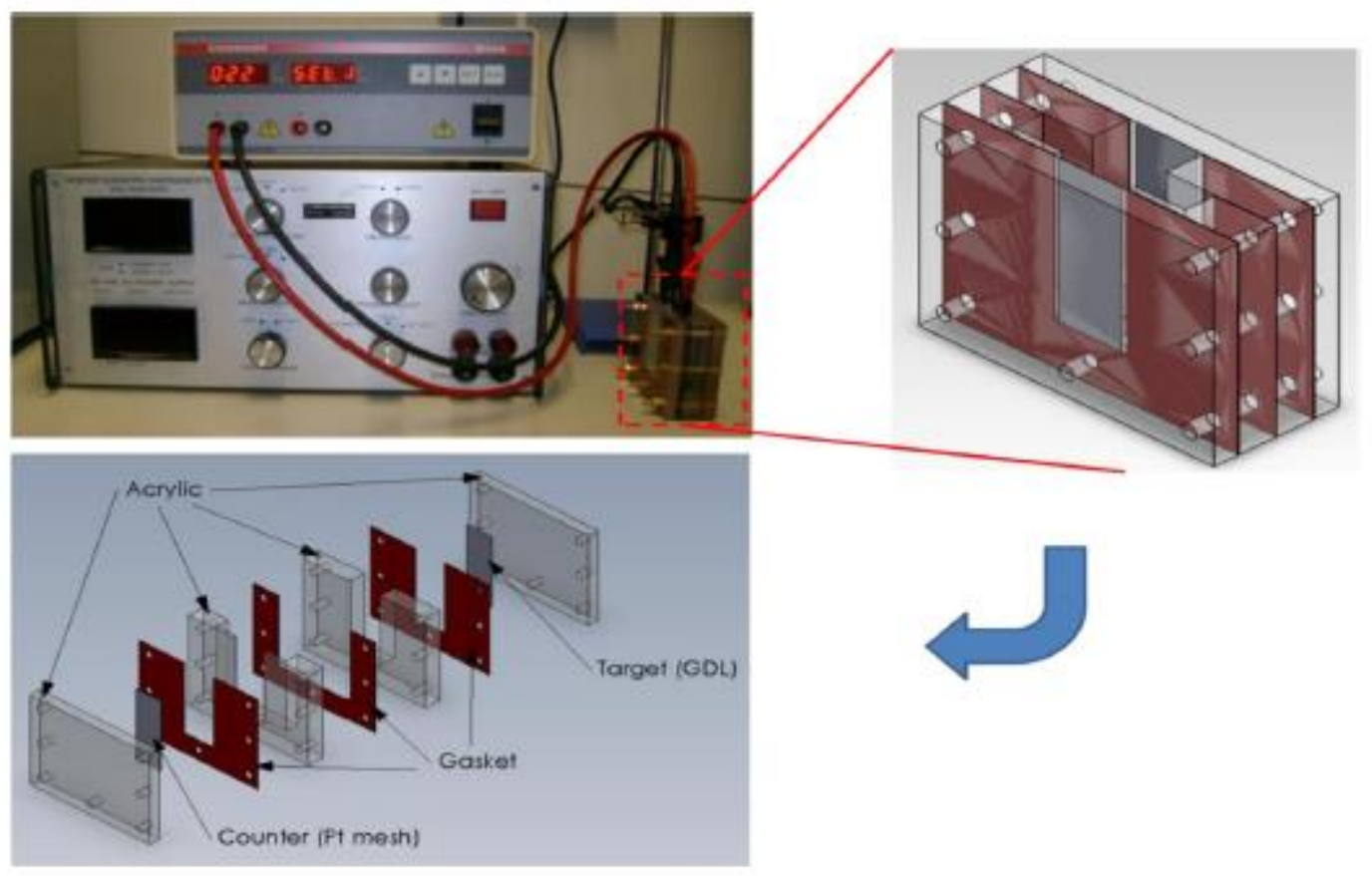

Fig. 4 Schematic diagram of EPD setup and cell. 


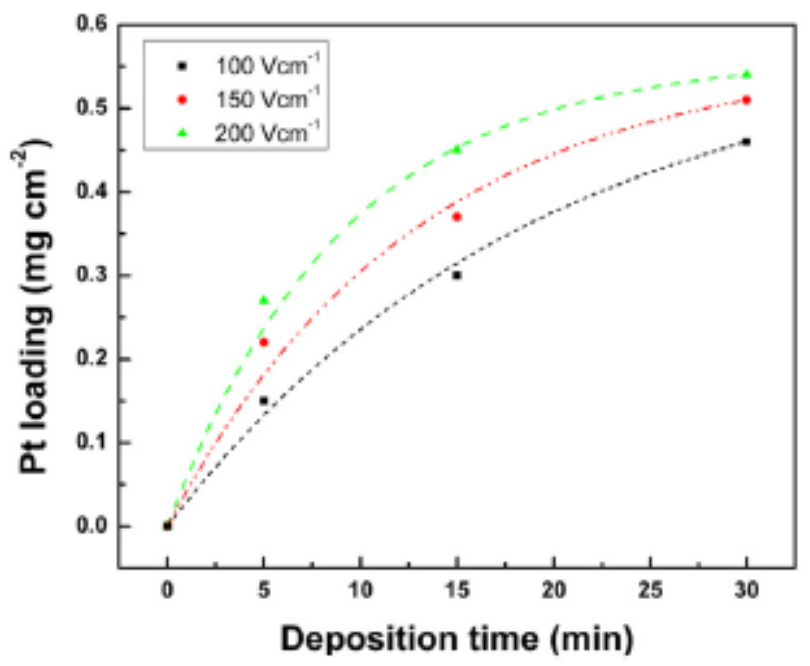

Fig. 5. Calibration curve for Pt loading vs electric field strengths.

Fig. 6(a)e(c) shows the SEM images of GDEs fabricated at various applied electric field strengths. For comparison purposes, a HS GDE is shown in Fig. 6(d). For the fabrication of the HS GDE, a spray gun (Prona RH-CP, Taiwan) with nitrogen as carrier gas was used to spray the catalyst particles onto the GDL. The Nafion ${ }^{\circledR}$ content was fixed at 20 wt\% with respect to catalyst particles for all the GDEs. At 50,000x magnification (insert), no significant difference between HS and EPD GDEs is observed. All GDEs show a porous morphology which is important to ensure that reactant gases effectively diffuse to the catalyst sites. At 1000x magnification, the morphologies of the GDEs fabricated by the two methods are significantly different. The HS GDE exhibits minor cracks and large catalyst lumps. The morphologies of the EPD GDEs are dominated by cracks while no catalyst lumps are observed. The absence of large catalyst lumps could be due to the use of dilute catalyst suspensions during EPD, indicating a more uniform deposition. However, the crack dominated morphologies of the EPD GDEs are probably caused during the drying step (due to the evaporation of the solvent/water) since rather thick catalyst layers (w11 mm) are formed for a $0.4 \mathrm{mg} \mathrm{cm}^{-2} \mathrm{Pt}$ loading. However, fine cracks are regarded as beneficial for catalyst layer morphologies, as it provides gas access to reaction sites close to the membrane and increases catalyst utilisation [29]. Fig. 6(e) and (f) shows the back scattered images of the EPD GDE fabricated at $100 \mathrm{~V} \mathrm{~cm}^{-1}$ and the HS GDE respectively. The EPD GDE exhibits better dispersion of the Pt catalyst particles than the HS GDE which promotes improved TPBs formation. The better dispersion of Pt particles in the EPD GDE is probably a result of using a more dilute catalyst suspension. Fig. 7 shows mercury intrusion porosity results obtained for HS GDE and EPD GDE fabricated at $100 \mathrm{~V} \mathrm{~cm}^{-1}$. Intrusion of mercury into different size pores occurs at different pressures. At low pressures, mercury moves into the larger pore diameters while at low pressures, mercury is forced into the smaller pore diameters. By applying a pressure range from low to high pressure values, a complete analysis of the porosity of the sample is obtained. The figure shows a distinct difference between the HS GDE and EPD GDE. The HS GDE shows no pores diameter $>100$ $\mathrm{mm}$ while the EPD GDE shows pore diameters up to w1000 $\mathrm{mm}$. The larger pore diameters 
present for the EPD GDE is most probably a result of the cracked morphology as observed by SEM analysis. The EPD GDE also shows more prominent peaks in the smaller pore diameter region than the HS GDE. This clearly indicates the presence of a larger number of smaller pores for the EPD GDE than the HS GDE.

These smaller pore diameters are beneficial for MEA performance. The EPD GDE had a total pore area of $22.46 \mathrm{~m}^{2} \mathrm{~g}^{-1}$ and the HS GDE had a total pore area of $13.43 \mathrm{~m}^{2} \mathrm{~g}^{-1}$, as obtained by the mercury porosimeter.

\subsection{Single cell test}

Based on the Pt loading calibration curve, all the EPD samples were fixed at $0.4 \mathrm{mg} \mathrm{cm}^{-2} \mathrm{Pt}$ for both the anode and cathode in this section. Fig. 8 shows the polarisation curves of EPD MEAs with various Nafion ${ }^{\circledR}$ contents. The MEA with 10 wt\% Nafion ${ }^{\circledR}$ shows a slightly higher performance than the samples with 20 and 30 wt\% Nafion ${ }^{\circledR}$ during the polarisation curve measurements. A slight decrease in MEA performance is immediately observed as the Nafion ${ }^{\circledR}$ content increases from 10 to $20 \mathrm{wt} \%$. This is because Nafion ${ }^{\circledR}$ is not a suitable ionomer/binder material for HT PEMFCs as it needs to be kept hydrated for optimum proton conduction. From Figs. 1 and 2 it is clear that the addition of Nafion ${ }^{\circledR}$ to the Pt/C particles yields good suspension stability, therefore Nafion ${ }^{\circledR}$ was selected as model material for fabrication of EPD GDEs for HT PEMFCs. Although 10 wt\% Nafion ${ }^{\circledR}$ content shows higher MEA performance, it shows least stability during the $3 \mathrm{~h}$ activation period. Therefore, 20 wt\% Nafion ${ }^{\circledR}$ content was selected for all further studies. Optimum Nafion ${ }^{\circledR}$ content is affected by both the Pt loading as well as the method of catalyst layer formation. Louh et al. [12] observed optimum performance at $40 \mathrm{wt} \%$ Nafion ${ }^{\circledR}$ content for a $0.16 \mathrm{mg} \mathrm{cm}^{-2}$ Pt loading via the EPD method while Huang et al. [30] observed best MEA performance at $33 \mathrm{wt} \%$ Nafion ${ }^{\circledR}$ content for a $0.3 \mathrm{mg} \mathrm{cm}^{-2}$ Pt loading via ultrasonic spray coating method, both for LT PEMFCs.

Fig. 9 shows the polarisation curves of EPD MEAs with 20 wt\% Nafion ${ }^{\circledR}$ and catalyst layers deposited at various applied electric field strengths. The result indicates that the lower applied electric field strength $\left(100 \mathrm{~V} \mathrm{~cm}^{-1}\right)$ yields a higher MEA performance. Basu et al. [31] found that higher quality deposits are obtained at moderate applied electric field strengths (25e100 $\mathrm{V} \mathrm{cm}^{-1}$ ) whereas the deposit quality deteriorates at higher applied electric field strengths $\left(>100 \mathrm{~V} \mathrm{~cm}^{-1}\right)$. Particle deposition at the electrode is a kinetic phenomenon therefore the particle accumulation rate affects the particle packing behaviour in the deposit. Higher applied electric field strengths are also known to cause more turbulent particle movement that lead to uneven deposited layers. Since the EPD process is selective towards smaller particles, it may be possible that at higher electric field strengths, larger particles also deposit due to the stronger driving force. SEM images exhibits greater roughness and wider cracks for GDEs fabricated at stronger applied

\section{http://repository.uwc.ac.za}


electric field strengths. Based on the polarisation results, the morphology of GDEs obtained at $100 \mathrm{~V} \mathrm{~cm}^{-1}$ is more favourable for the formation of TPBs required for high MEA performance.

Fig. 10 shows the stability behaviour of the HS MEA and the EPD MEA (100 $\left.\mathrm{V} \mathrm{cm}^{-1}\right)$ at a constant cell voltage of $0.55 \mathrm{~V}$ for $48 \mathrm{~h}$. Both MEAs show similar stability with decrease in current density less than $4 \%$ after $48 \mathrm{~h}$. The EPD MEA had w10 $\mathrm{mA} \mathrm{cm}^{-2}$ higher current density at $0.55 \mathrm{~V}$ than the HS MEA which remained constant over than $48 \mathrm{~h}$ period.

Fig. 11(a) shows the polarisation curves of the HS MEA and EPD MEA (100 $\mathrm{V} \mathrm{cm}^{-1}$ ). For peak power, the MEA fabricated by EPD method exhibits up to $73 \%$ higher power compared to the HS MEA. The significant difference in MEA performance can be explained based on the difference in GDE morphology. SEM analysis clearly shows that the EPD GDEs possess significant cracks which probably benefits MEA performance. Back scattered images also show a better dispersion of the Pt particles in the catalyst layer of the EPD GDE than the HS GDE. This observation suggests improved TPB formation for the EPD MEA compared to the HS MEA. Mercury intrusion porosity measurements confirm that the EPD GDEs possess larger pore diameters as well as a greater abundance of smaller pore diameters, allowing easy access for gaseous reactants to the catalyst sites. 


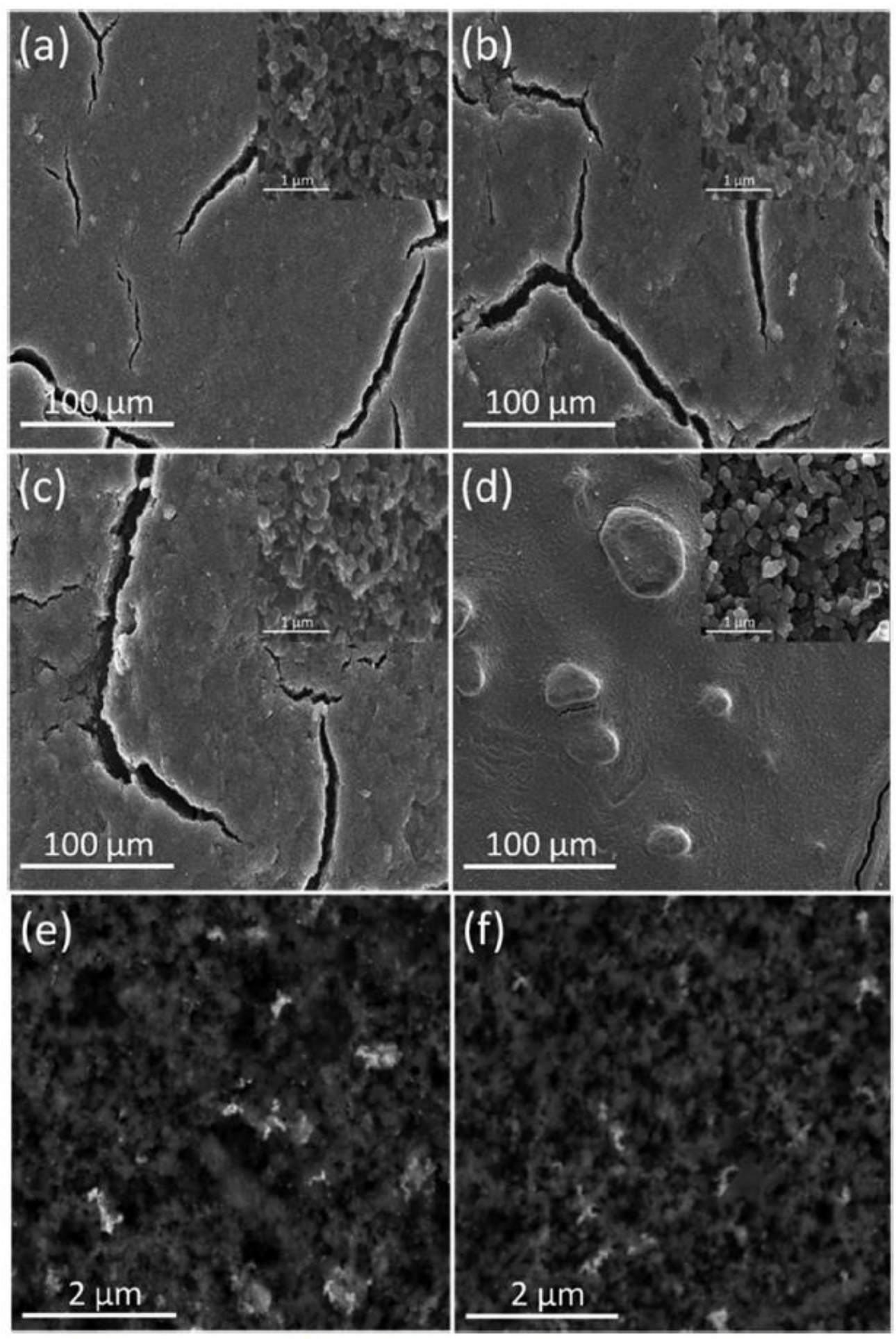

Fig. 6. (a) SEM image of EPD GDE fabricated at $100 \mathrm{~V} \mathrm{~cm}^{-1}$. (b) SEM image of EPD GDE fabricated at $150 \mathrm{Vcm}^{-1}$. (c) SEM image of EPD GDE fabricated at $200 \mathrm{~V} \mathrm{~cm}-1$. (d) SEM image of HS GDE (e) Back scattered image of EPD GDE fabricated at $100 \mathrm{Vcm}^{-1}$. (f) Back scattered image of HS GDE. 


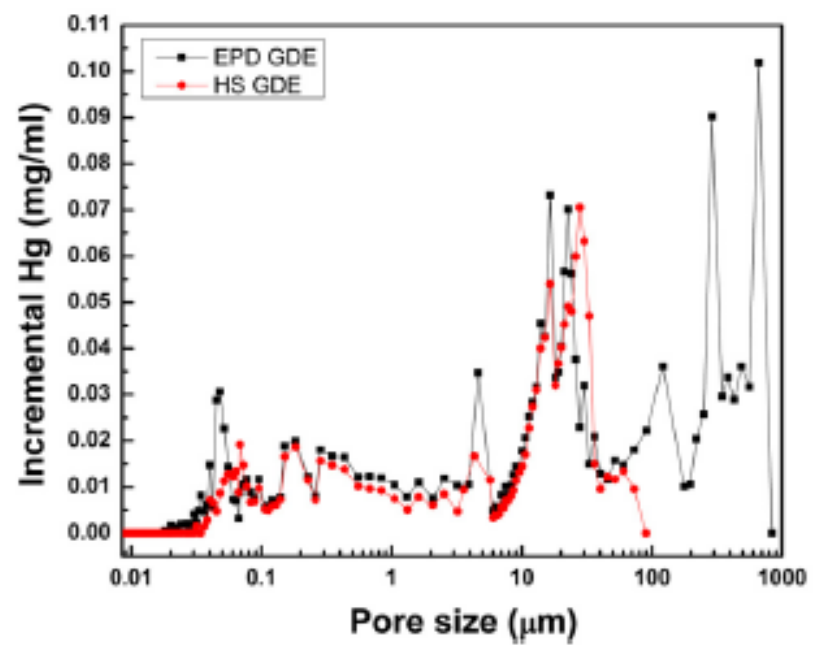

Fig. 7. Mercury intrusion porosity of HS GDE and EPD GDE fabricated at $100 \mathrm{~V} \mathrm{~cm}^{-1}$.

Fig. 11(b) shows the $I R$ free polarisation curves of the HS MEA and EPD MEA (100 V $\mathrm{cm}^{-1}$ ). Internal resistance were corrected based on the high frequency resistance of $A C$ impedance. Under low current load, the HS and EPD MEAs display similar performance which implies that the activities of catalysts are similar because the same catalyst material was used for both MEA types. Under higher current load a significant difference in MEA performance is observed. Under higher current loads, a higher relative mass transport resistance is observed for the HS MEA. The EPD GDE has a larger pore area than the HS GDE, allowing easier access for gaseous reactants to the catalyst sites; therefore a better performance is expected for the EPD MEA, especially under higher current load. 


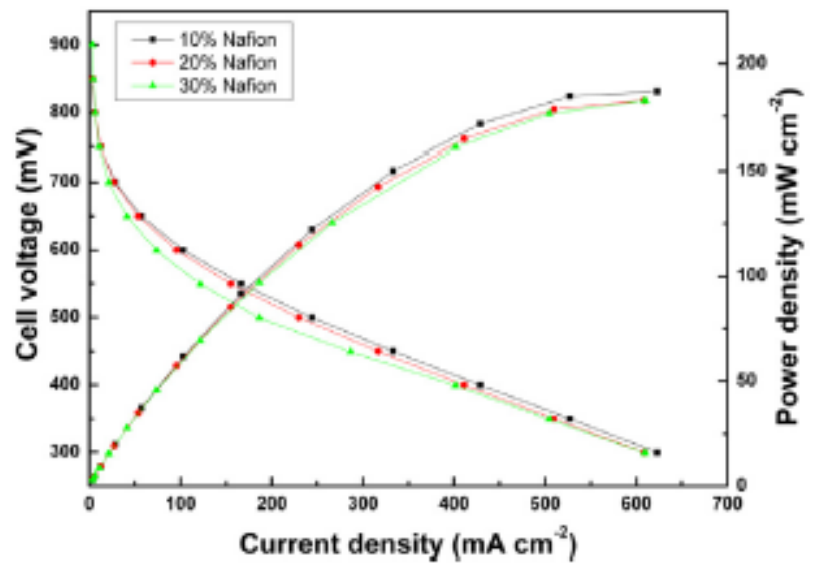

Fig. 8. Polarisation curves of MEAs with EPD GDEs fabricated at $100 \mathrm{~V} \mathrm{~cm}^{-1}$ with various Nafion ionomer contents.

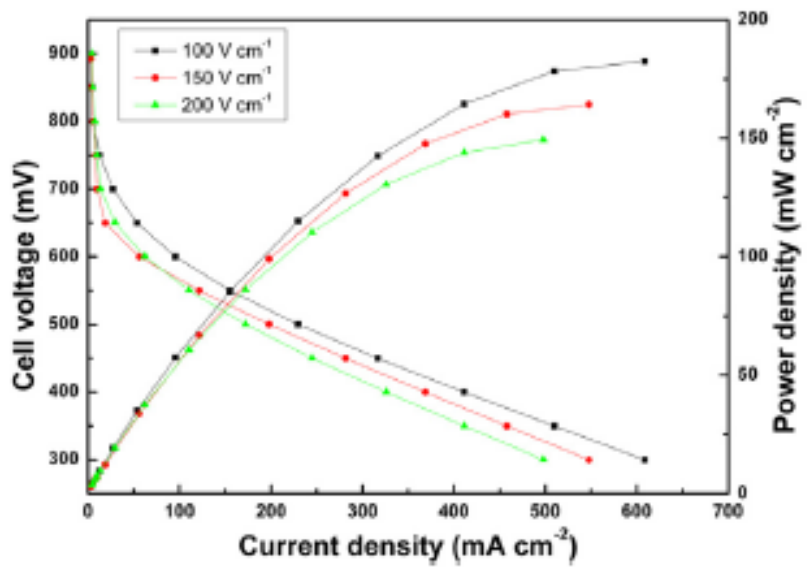

Fig. 9. Polarisation curves of MEAs with EPD GDEs fabricated under various applied electric field strengths with $20 \mathrm{wt} \%$ Nafion ionomer content.

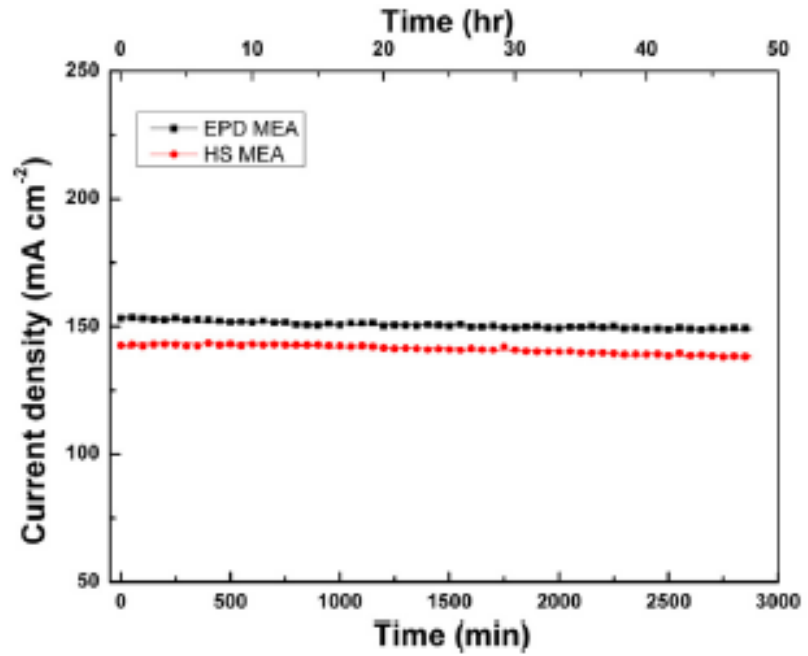

Fig. 10. Stability behaviour of MEAs with HS GDEs and EPD GDEs $\left(100 \mathrm{Vcm}^{-1}\right)$ at $0.55 \mathrm{~V}$. 
Fig. 12 shows EIS spectra of HS MEA and EPD MEA (100 $\left.\mathrm{V} \mathrm{cm}^{-1}\right)$ under $300 \mathrm{~mA} \mathrm{~cm}^{-2}$ current loads. The left intercept of the impedance arc is due to the high frequency response and represents the total ohmic resistance of the cell. The total ohmic resistance is due to cell components such as the membrane, catalyst layer, gas diffusion layer (inc. MPL) and bipolar plates [32]. The EPD and HS MEAs exhibits comparable behaviour in the high frequency range which implies that the ohmic resistances of the two MEAs were comparable. The charge transfer resistance, represented by the diameter of the arc is the resistance dominated by the oxygen reduction reaction. The charge transfer resistance is much lower for the EPD MEA than HS MEA and leads to a significantly higher performance. The lower charge transfer resistance indicates that the EPD method is more suitable to fabricate GDEs for HT PEMFCs than the HS method.
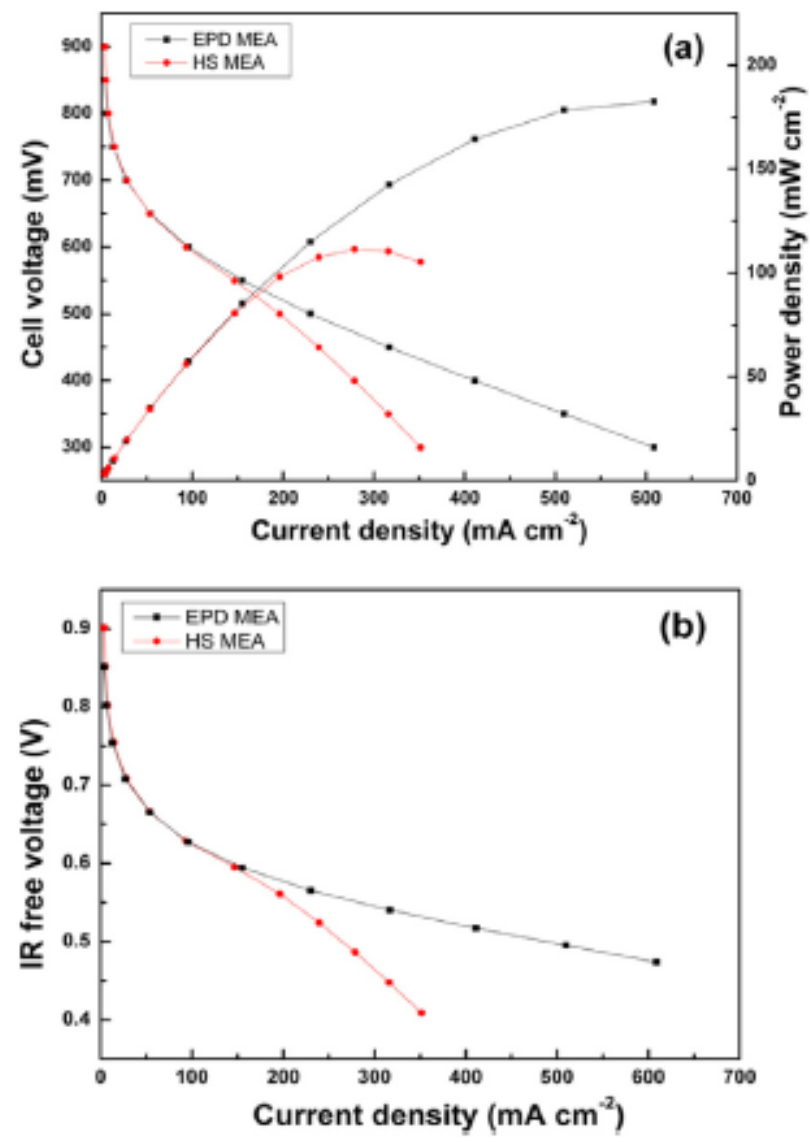

Fig. 11. (a) Polarisation curves and (b) IR free polarisation curve of MEAs with HS GDEs and EPD GDEs fabricated at $100 \mathrm{Vcm}^{-1}$. 


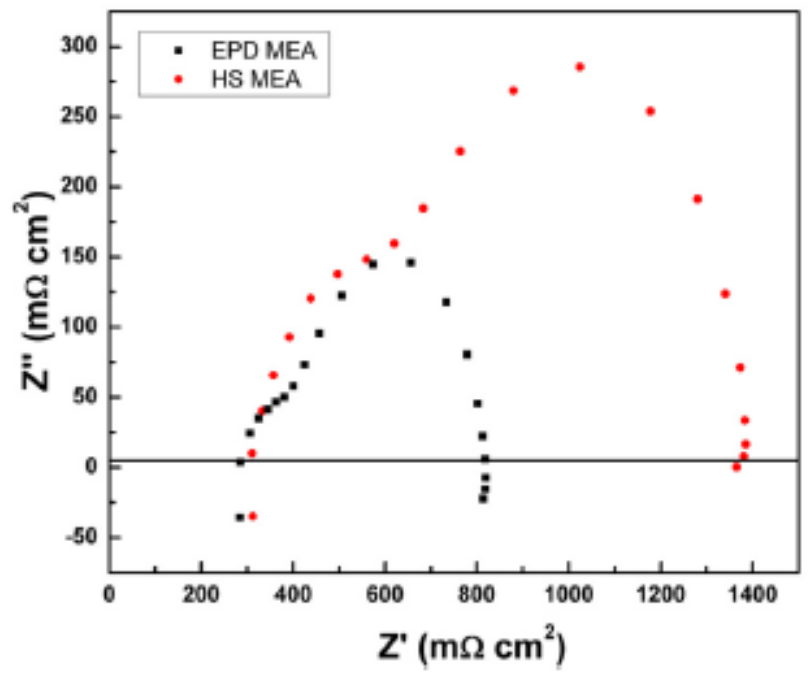

Fig. 12. EIS of MEAs with HS GDEs and EPD GDEs (100 $\left.\mathrm{V} \mathrm{cm}^{-1}\right)$ under $300 \mathrm{mAcm}^{-2}$ current bad.

\section{Conclusions}

Optimum suspensions to fabricate GDEs via EPD are those containing Nafion ${ }^{\circledR}$ ionomer with its $\mathrm{pH}$ adjusted between 8 and 10. These suspensions yield good stability and sufficient conductivity to form catalyst layers on top of GDLs. Higher applied electric field strengths $\left(>100 \mathrm{~V} \mathrm{~cm}^{-1}\right)$ negatively affects MEA performance while increasing Nafion ${ }^{\circledR}$ content ratio (up to $30 \mathrm{wt} \%$ ) only slightly affects MEA performance. Single cell tests show that MEAs fabricated by the EPD method performs better than the HS MEAs due to a lower charge transfer resistance. This study shows that EPD is more suitable than the traditional HS method to fabricate GDEs for HT PEMFCs even though the highest performance in this study is only ca. $180 \mathrm{~mW} \mathrm{~cm}^{-2}$. The reason for the low MEA performance is due to Nafion ${ }^{\circledR}$ not being a suitable ionomer/binder for high temperature MEAs. However, the Nafion ${ }^{\circledR}$ ionomer serves as good model material to investigate the EPD method for GDE fabrication for high HT PEMFCs. Future studies will investigate other polymer/ionomers to fabricate GDEs via the EPD method.

\section{Acknowledgement}

This work was supported by the Hydrogen and Fuel Cell Technologies RDI Programme (HySA) funded by the Department of Science and Technology in South Africa (Project KP1So1). 


\section{References}

[1] A. Verma, S. Basu, J. Power Sources 135 (2004) $62 \mathrm{e} 65$.

[2] M. Carmo, A.R. dos Santos, J.G.R. Poco, M. Linardi, J. Power Sources 173 (2007) 860e866.

[3] Y. Shao, G. Yin, Z. Wang, Y. Gao, J. Power Sources 167 (2007) 235e242. [4] T.-L.L. Yu, H.-L. Lin, Open Fuels Energy Sci. J. 3 (2010) 1 e7.

[5] A. Therdthianwang, P. Ekdharmasuit, S. Therdthianwang, Energy Fuels 24 (2010) $1191 \mathrm{e} 1196$.

[6] N. Rajalakshmi, K.S. Dhathathreyan, Chem. Eng. J. 129 (2007) 31e40.

[7] R.N. Bonifacia, J.O.A. Pascoal, M. Linardi, R. Cuenca, J. Power Sources 196 (2011) $4680 \mathrm{e} 4685$.

[8] L. Stappers, L. Zhang, O. Van Der Biest, J. Fransaer, J. Colloid Interface Sci. 328 (2008) $436 \mathrm{e} 446$.

[9] A.R. Boccaccini, J. Cho, J.A. Roether, B.J.C. Thomas, E.J. Minay, M.S.P. Shatter, Carbon 44 (2006) 3149e3160.

[10] I. Corni, M.P. Ryan, A.R. Boccaccini, J. Eur. Ceram. Soc. 28 (2008) 1353 e1357. [11] H. Munakata, T. Ishida, K. Kanamura, J. Electrochem. Soc. 154 (12) (2007)

B1368eB1372.

[12] R.F. Louh, H. Huang, F. Tsai, J. Fuel Cell Sci. Technol. 4 (2007) $72 e 78$.

[13] R.F. Louh, A.C.C. Chang, V. Chen, D. Wong, Int. J. Hydrogen Energy 33 (2008) 5199e5204.

[14] K.-T. Jeng, W.-M. Huang, N.-Y. Hsu, Mater. Chem. Phys. 113 (2009) $574 \mathrm{e} 578$.

[15] H. Morikawa, N. Tsuihiji, T. Mitsui, K. Kanamura, J. Electrochem. Soc. 151 (2004) A1733eA1737.

[16] J.T. Wang, R.F. Savinell, J. Wainright, M. Litt, H. Yu, Electrochim. Acta 41 (2) (1996) $193 \mathrm{e} 197$.

[17] P. Krishnan, J. Park, C. Kim, J. Power Sources 159 (2006) 817e823.

[18] S. Jiménez, J. Soler, R.X. Valenzuela, L. Daza, J. Power Sources 151 (2005) 69e73.

[19] T. Fujigaya, M. Okamoto, N. Nakashima, Carbon 47 (2009) $3227 e 3232$.

[20] Y. Song, Y. Wei, H. Xu, M. Williams, Y. Liu, L.J. Bonville, H.R. Kunz, J.M. Fenton, J. Power Sources 141 (2005) $250 e 257$.

[21] Q. Li, J.O. Jensen, R.F. Savinell, N.J. Bjerruma, Prog. Polym. Sci. 34 (2009) $449 \mathrm{e} 477$.

[22] C. Wannek, W. Lehnert, J. Mergel, J. Power Sources 192 (2009) 258 e266. [23] J.C.W. Corbett, R.O. Jack, Colloids Surf. A 376 (2011) 31e41.

[24] O.O. Van Der Biest, L.J. Vandeperre, Annu. Rev. Mat. Sci. 29 (1999) 327e352. [25] L. Besra, M. Lui, Prog. Mater. Sci. 52 (2007) 1 e61.

[26] J.-H. Lee, U. Paik, J.-Y. Choi, K.K. Kim, S.-M. Yoon, J. Lee, B.-K. Kim, J.M. Kim, M.H. Park, C.W. Yang, K.H. An, Y.H. Lee, J. Phys. Chem. C 111 (2007) 2477 e2483. [27] X. Ye, T. Narayanan, P. Tong, J.S. Huang, M.Y. Lin, B.L. Carvalho, L.J. Fetters, 
Phys. Rev. E 54 (6) (1996) 6500e6510.

[28] G. Fritz, V. Schädler, N. Willenbacher, N.J. Wagner, Langmuir 18 (2002) $6381 \mathrm{e} 6390$.

[29] S. Lister, G. Mclean, J. Power Sources 130 (2004) $61 \mathrm{e} 76$.

[30] T.-H. Huang, H.-L. Sheng, T.-C. Jao, F.-B. Wang, A. Su, Int. J. Hydrogen Energy 37 (2012) $13872 \mathrm{e} 13879$.

[31] R.N. Basu, C.A. Randall, M.J. Mayo, J. Am. Ceram. Soc. 84 (1) (2001) 33e40. [32] X. Yuan, H. Wang, J.C. Sun, J. Zhang, Int. J. Hydrogen Energy 32 (2007) $4365-4380$ 